\title{
DNA analysis of human skeletal remains associated with the Batavia mutiny of 1629
}

\author{
Padillah Yahya', Silvana Gaudieri',2 and Daniel Franklin ${ }^{1}$ \\ ${ }^{1}$ Centre for Forensic Science, University of Western Australia, Crawley, Western Australia 6009, \\ Australia. \\ ${ }^{2}$ School of Anatomy and Human Biology, University of Western Australia, Crawley, Western Australia \\ 6009, Australia. Corresponding author — email: daniel.franklin@uwa.edu.au
}

\begin{abstract}
The wrecking of the Verenigde Oostindische Compagnie retourschip Batavia, and the subsequent massacre that ensued, is one of the most macabre events in the history of pre-colonial European activity in Australia. Human skeletal remains have been recovered during the excavation of sites on Beacon Island in the Houtman Abrolhos that are associated with the Batavia mutiny. Four individual burials were discovered between 1960 and 1964 and a further six individuals (including children) were recovered from a multiple burial excavated between 1994 and 2001.

The physical remains of those victims of the Batavia mutiny were previously analysed in order to estimate age, sex, stature and to describe their general state of health and any evidence of perimortem trauma that may have contributed to death. These data were interpreted in relation to historical and archaeological evidence to postulate who the individuals may have been, and to rule out other potential burials that occurred during the mutiny. There are, however, some inherent limitations with the anthropological analyses: first, familial relationships cannot be ascertained from the physical remains; second, it is not possible to reliably estimate sex in the immature skeleton. To that end, the aim of the present project is to study the familial relationships of the almost 400 -year-old remains and to determine their sex based on molecular genetic analysis.
\end{abstract}

Teeth from nine of the victims were available for DNA analysis. Following extraction and decontamination, the pulp chamber of the tooth was drilled and powdered sample collected. With regard to sex estimation, attempts to type the amelogenin gene on chromosomes $X$ and $Y$ were ultimately unsuccessful, most likely due to the overall poor preservation of the remains. DNA analyses of the hypervariable regions within the maternally inherited mitochondrial genome, however, suggest that there is no maternal relationship between two of the children in the multiple burial, which has important ramifications for establishing potential identifications of the victims.

KEYWORDS: molecular anthropology; physical anthropology.

\section{INTRODUCTION}

The Verenigde Oostindische Compagnie (VOC) retourschip Batavia was commissioned in the $17^{\text {th }}$ century to take advantage of lucrative trade opportunities in Asia. The Batavia, together with a fleet of six other vessels, departed Amsterdam on 29 October 1628; their planned destination was Batavia (modern day Jakarta). Packed on board were approximately 316 people, including enlisted sailors, VOC officers, passengers (including women and children) and a complement of soldiers en-route to Java to fight in the active war against the ruler of Mataram (DrakeBrockman 1963). Whether by accident or design, however, the Batavia never reached the waters of Asia, having wrecked on Morning Reef in the Houtman Abrolhos, off Australia's west coast on 4 June 1629. The ship's commandeur, Francisco Pelsaert, had survivors landed on nearby Beacon Island, and then embarked on a rescue voyage. During Pelsaert's absence, an unsuccessful mutiny attempt resulted in the murder of at least 125 people (van Huystee 1998).

Although the Batavia mutiny is historically well known, both from detailed VOC records (in particular Pelsaert's journal) and a popular contemporary Dutch novel (Ongeluckige Voyagie van't Schip Batavia - first published in 1647 by Jan Jansz) the precise location of the wreck site was reportedly not 'officially substantiated' until 1963 (Stanbury 1998). The first of four individual burials on Beacon Island, however, were actually discovered in 1960, by resident fisherman 'Pop' Marten. The area around that burial revealed the first datable artefact (an engraved trumpet bell garland) that conclusively associated the Beacon Island site with the Batavia, although their connection was not realised until 
several years later (Stanbury 1998).

A further three individual burials were recovered between 1963 and 1964, during expeditions led by teams that included, amongst others, Max Cramer and Hugh Edwards. Under the direction of the Western Australian Museum, and in collaboration with various forensic specialists, six more individuals, albeit poorly preserved, were recovered from a multiple burial excavated between 1994 and 2001. Some brief descriptions of the multiple burial have been published (e.g. Pasveer et al. 1998; Pasveer 2000). With regard to identifying the victims, an early hypothesis that was investigated was whether the multiple burial was associated with the slaughter of the Predicant's (the Batavia's official minister) family, including his wife, maid and six of their seven children; two girls, three boys and a baby (Pasveer 2000). Subsequent research, however, demonstrated that the grave was highly unlikely to contain the Predicant's family (see below).

More detailed analyses of the total sample were subsequently made by Franklin (2001) and Franklin and Freedman (2006) in which characteristics of the multiple burial, such as the age, sex, numbers and positioning of the individuals interred, evidence of trauma and the nature of the burial itself were analysed. That data were then compared for any similarity or dissimilarity to individuals listed and events outlined and chronologically recorded in VOC records, in an attempt to ascertain who was buried in the multiple burial. It was proposed that the most plausible theory was that the interred were probably sick individuals who were among the early victims of the massacre (for further discussion see Franklin and Freedman 2006). Further, the evidence recovered from the grave did not support the Predicant family hypothesis; there was no visible cranial trauma (the supposed cause of death) and the numbers of individuals recovered, and their age and sex, does not match the historical records that describe the family and how they were killed.

There is only a limited amount of information that can be gleaned from osteological evidence alone, especially when it is poorly preserved. Ancient DNA (aDNA) analysis, which involves the analysis of DNA from specimens hundreds to thousands years of age, has been widely used on archaeological and museum specimens to assess familial relationships and for sex estimation (Palmirotta et al. 1997; Meyer et al. 2000; Rudbeck et al. 2005; Ricaut et al. 2006). The combination of archaeological data with molecular evidence, however, affords new opportunities to study the life history of the Batavia mutiny victims thus far recovered. To that end, the first objective of the present study is to establish if there are any familial relationships between the recovered individuals. This evidence is especially important in placing the multiple burial in its correct historical context; although the physical and historical evidence suggests that it is extremely unlikely that these remains are those of the Predicant's family (see above), the only conclusive answer is in their DNA, especially considering historical sources can be inherently biased and/or inaccurate (Wood 1990).

The second objective is to determine the sex of each individual based on molecular genetic analysis, thus removing the subjectivism associated with assigning sex based on skeletal morphology. This is particilarly important with regard to the juveniles in the sample (SK8 and SK9) as it is practically impossible to reliably estimate sex in the skeleton of a non-adult individual.

TABLE 1 Main features of the Batavia skeletal material including proposed associations (/) of cranial and postcranial skeletons.

\begin{tabular}{|c|c|c|c|c|}
\hline Individual & Description & Sex & Age-range* $^{*}$ & Stature $^{\dagger}$ \\
\hline & \multicolumn{4}{|l|}{ Individual Burials } \\
\hline M3901 & Calvaria + postcranial skeleton & Female & $18-20$ yrs & $1.61 \mathrm{~m}$ \\
\hline A15831 / A15508 & Skull + postcranial skeleton & Male & $19-21 \mathrm{yrs}$ & N/A \\
\hline A15507 & Skull + postcranial skeleton & Male & $20-34$ yrs & $1.82 \mathrm{~m}$ \\
\hline \multirow[t]{2}{*}{ A16316 } & Cranium & Male & $20-34$ yrs & N/A \\
\hline & \multicolumn{4}{|l|}{ Multiple Burial } \\
\hline SK5 / SK11 & Cranium + postcranial skeleton & Male & $35-49$ yrs & $1.74 \mathrm{~m}$ \\
\hline SK6 / SK10 & Cranium + postcranial skeleton & Male & $35-49$ yrs & $1.79 \mathrm{~m}$ \\
\hline SK7 & Skull + postcranial skeleton & Male & $20-34$ yrs & $1.76 \mathrm{~m}$ \\
\hline SK8 & Skull + postcranial skeleton & Male? & $15-16 \mathrm{yrs}$ & $1.51 \mathrm{~m}$ \\
\hline SK9 & Skull + postcranial skeleton & N/A & $5-6$ yrs & N/A \\
\hline SK12 & Deciduous + permanent teeth & N/A & $8-9$ mo & N/A \\
\hline
\end{tabular}

${ }^{*}$ yrs = years; mo = months; $†$ reconstructed mean stature; N/A not able to be determined. 

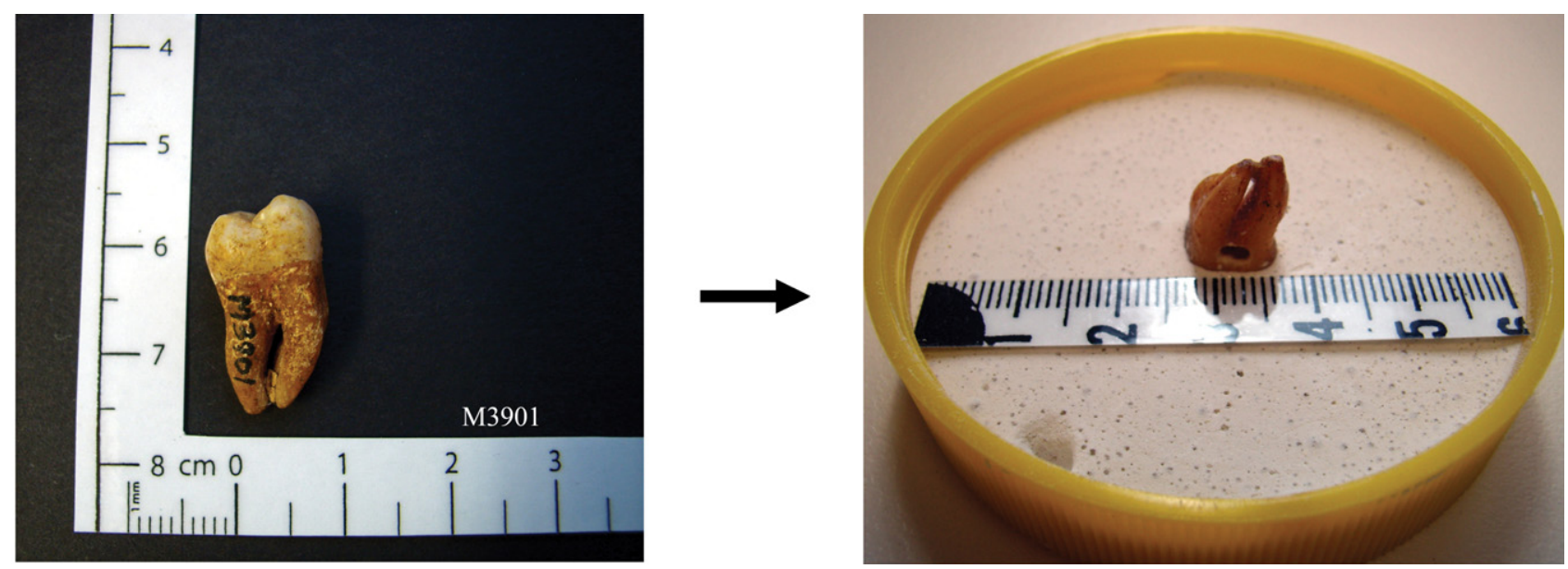

FIGURE 1 Buccal view of the left mandibular second molar of individual M3901: before decontamination and preparation (left); and following mounting and drilling (right).

In this study, the hypervariable regions within the D-loop of the maternally-inherited mitochondrial DNA (mtDNA) were targeted to determine familial relationships. Although mtDNA variation provides less discrimination power at the individual level than nuclear DNA, it can be used as a marker of the maternal line as it is transmitted to offspring relatively unchanged for several generations due to a lack of recombination. The analysis of these regions to determine familial relationships within burial groups has become widely employed (Keyser-Tracqui et al. 2003). Sex estimation of the skeletal remains was attempted by analysing the amelogenin gene present on the X- and Y-chromosomes. Differentiation between female and male individuals is possible due to deletions within the amelogenin gene on the X and/or Y chromosomes (Sullivan et al. 1993).

\section{MATERIALS}

So far the skeletal remains of ten individuals have been found on Beacon Island; the basic demographic profile of each individual, on the basis of an anthropological assessment (Franklin and Freedman 2006), is summarised in Table 1. For the current study, a single molar was extracted from nine of the ten individuals (the dentition of SK12 was too immature for viable analysis). As excessive occlusal attrition will expose underlying dentine and potentially compromise the integrity of the tooth, the molar with the least amount of wear (generally the second or third) was extracted where possible. Prior to decontamination and drilling, all of the teeth were photographed and measured; museum quality casts of each individual tooth were made as a contingency for potential damage.

\section{METHODS}

\section{SAMPLE DECONTAMINATION AND PREPARATION}

Appropriate decontamination was performed to avoid aDNA sample contamination from exogenous
DNA. Following published protocols (e.g. Hummel and Hermann 1994; Kemp and Smith 2005; Bouwman et al. 2006; for complete list see Yahya 2008), the crown and root surfaces of each tooth were scraped and brushed clean with single use sterile scalpels and toothbrushes. The teeth were then thoroughly rinsed with sterile distilled water and dried using sterile gauze. The external surface of each tooth was wiped with $20 \%$ commercial bleach using a sterile gauze pad, followed immediately with a wipe-down using 95\% ethanol; the teeth were then allowed to air-dry under UV irradiation $(254 \mathrm{~nm})$ on each side for 30 minutes. In preparation for drilling the crown of each molar was coated with several layers of wax; the tooth was then embedded in plaster at the level of the cemento-enamel junction (Figure 1). This mounting technique was designed to minimise potential damage to the tooth during the drilling process. The accessible parts of the tooth and the mounting apparatus were again decontaminated following the steps described above.

\section{SAMPLE COLLECTION}

Following mounting and secondary decontamination (see above) the pulp and dentin area were carefully removed using a dental drill; masks were worn and new drill-bits and gloves were used for each tooth. The work space and all equipment were decontaminated between drilling each tooth using $20 \%$ bleach and $95 \%$ ethanol. The powder was collected in sterilised $1.5 \mathrm{ml}$ eppendorf tubes; the weight of each sample varied from 8.8 to 39.5 mg (Table 2). All of the powder was used in the DNA extraction process.

\section{DNA EXTRACTION}

The tooth powder was decalcified in $0.5 \mathrm{M}$ EDTA $\mathrm{pH} 8.0$ at room temperature overnight. Following decalcification, samples underwent protein digestion in $700 \mu \mathrm{l}$ extraction buffer $(10 \mathrm{mM}$ Tris- $\mathrm{HCl} \mathrm{pH} 8.0$; $100 \mathrm{mM} \mathrm{NaCl}, 50 \mathrm{mM}$ EDTA pH 8.0, 0.5\% SDS) and Proteinase $\mathrm{K}(20 \mathrm{mg} / \mathrm{ml})$, and then incubated at $56^{\circ} \mathrm{C}$ overnight. Extraction negative controls were included at 
this step. DNA in the samples were then isolated using $700 \mu \mathrm{l}$ Phenol/Chloroform/Isoamyl alcohol (25:24:1) solution and concentrated using a Microcon YM-30 (Millipore). Samples were purified using QIAquick PCR Purification Kits (Qiagen) as per the manufacturer's instructions resulting in a final volume of $50 \mu \mathrm{l}$.

\section{PCR AMPLIFICATION}

\section{i) Hypervariable regions 1 and 2 (HV1 and 2) of the $m t D N A$}

PCR conditions were optimised on positive control samples (see Yahyah 2008 for specific optimisation protocols). A previously described multiplex PCR was used to amplify the HV1 and HV2 regions of the mtDNA (Hummel 2003). The expected amplicon sizes were $131 \mathrm{bp}$ and $168 \mathrm{bp}$ for HV1 and $217 \mathrm{bp}$ and $312 \mathrm{bp}$ for HV2. Successful reactions were purified using the QIAquick PCR Purification Kit (Qiagen) for DNA sequencing.

\section{ii) Amelogenin typing}

The method of Sullivan et al. (1993) was employed to amplify intron 1 of the amelogenin gene on both sex chromosomes. As the X-chromosome has a $6 \mathrm{bp}$ deletion in the targeted region, expected amplicon sizes were $112 \mathrm{bp}$ for the Y-chromosome and $106 \mathrm{bp}$ for the X-chromosome. Amplicon size was determined by running the PCR amplicons on a $4 \%$ agarose gel using an electric field. As an alternative amelogenin typing procedure, the AmpFlSTR ${ }^{\circledR}$ Profiler Plus ${ }^{\mathrm{TM}}$ PCR Amplification Kit (Applied Biosystems) was used according to the manufacturer's instructions with the exception of cycle number; 34 used instead of 28. This kit includes PCR primer sets that target 9 short tandem repeat (STR)-loci on the autosome chromosomes and the amelogenin gene. Samples were run on an ABI 3730xl sequencer and results were analysed using Genemapper.

TABLE 2 The weight $(\mathrm{mg})$ of powdered tooth samples collected from each individual; the FDI number designates which tooth was sampled.

\begin{tabular}{lll} 
Individual & Tooth (FDI) & Weight $(\mathrm{mg})$ \\
\hline M3901 & 37 & 27.5 \\
A15831 & 17 & 29.0 \\
A15507 & 27 & 39.5 \\
A16316 & 17 & 24.9 \\
SK5 & 17 & 20.8 \\
SK6 & 27 & 31.0 \\
SK7 & 16 & 8.8 \\
SK8 & 16 & 18.6 \\
SK9 & 65 & 18.8 \\
\hline
\end{tabular}

\section{DNA SEQUENCING AND ANALYSIS OF HV1 AND HV2 MTDNA AMPLICONS}

Successful reactions from the HV1 and HV2 mtDNA PCR underwent cycle sequencing using the ABI PRISM ${ }^{\circledR}$ Big Dye ${ }^{\circledR}$ Terminator v3.1 Cycle Sequencing Kit (BDT) (Applied Biosystems) as per the manufacturer's instructions. Samples were run on an ABI 3730x1 sequencer and electropherograms were analysed and edited using the Assign-SBT ${ }^{\mathrm{TM}}$ Software (Conexio Genomics). Mixtures were reported if, at any nucleotide position, two or more nucleotide peaks were observed and the intensity of the minor peak(s) was at $20 \%$ or more of the main peak. Mixtures were assigned according to the International Union of Pure and Applied Chemistry (IUPAC). Subsequently, sequences were aligned against the revised Cambridge Reference Sequence (rCRS) (Andrews et al. 1999) using the BLAST program (available at http://www.ncbi.nlm.nih. gov/blast).

\section{STEPS TAKEN TO AVOID CONTAMINATION}

Contamination is a major problem inherent to aDNA analysis. Here we attempted to minimise contamination by the following approaches: i) all extractions and analyses on the Batavia teeth samples were performed in a dedicated PCR DNA laboratory with strict separation of pre-PCR and post-PCR rooms including separation of reagents, equipment, coats and storage facilities; ii) use of UV lights and 70-80\% ethanol in fume hoods and on surfaces and equipment; iii) use of disposable filtered pipette tips, laboratory-ware, gloves and masks; iv) extraction controls and multiple negative PCR controls accompanied samples throughout each step; v) use of one tooth at a time; vi) replication of amplification; and vii) DNA typing of the personnel directly involved in handling samples.

\section{RESULTS}

\section{FAMILIAL RELATIONSHIPS - MITOCHONDRIAL DNA ANALYSIS}

The sequence of the HV1 and HV2 of mtDNA from the skeletal remains were analysed using a multiplex reaction (Hummel 2003). PCR amplicons (131 bp and $168 \mathrm{bp}$ ) corresponding to HV1 were successfully amplified in all nine samples. The third amplicon (217 bp) corresponding to HV2 was amplified in most samples; albeit these products were weaker (see Figure 2 for example). The largest amplicon (312 bp), which can be seen in exceptionally well-preserved samples, was not present in any of the samples. Several negative controls were run simultaneously with the samples and no PCR products were detected in any of the negative controls. However, it should be noted that a product of approximately 400 bp was consistently seen in all extraction blank samples, but no fragments corresponding to the expected amplicon sizes were amplified from the extraction blanks. This product was 


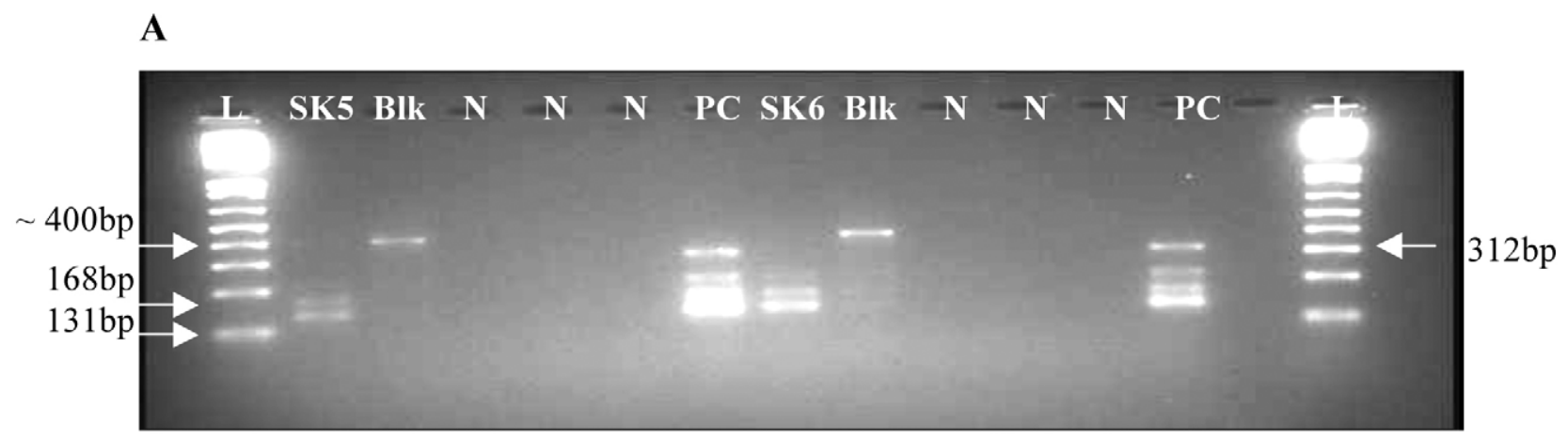

B

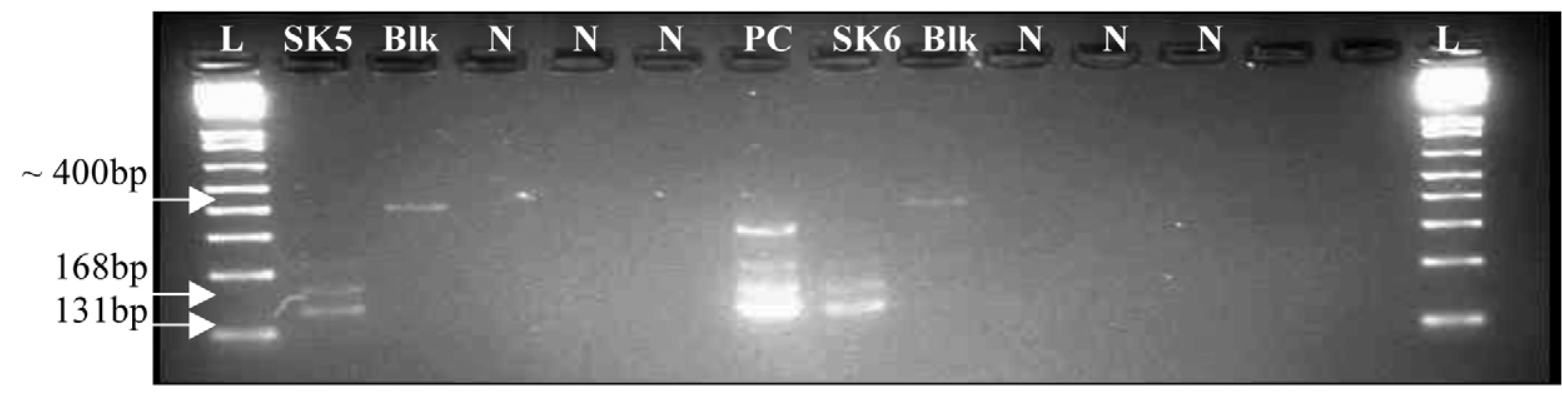

FIGURE 2 HV1 and HV2 amplification products for SK5 and SK6. (A) $1^{\text {st }}$ PCR amplification. (B) Repeated amplification. Blk is Extraction Blank, N is Negative Control, PC is Positive Control and L is 100 bp DNA Ladder.

not observed in any of the negative or positive controls, which indicated that it most likely did not come from the PCR reaction mix, or during PCR preparation. However, a faint band with the same (approximate $400 \mathrm{bp}$ ) size was also observed in the SK7 (second amplification), A15507 and A16316 samples (both amplifications). This fragment was not sequenced. All four amplicons (131 bp, $168 \mathrm{bp}, 217 \mathrm{bp}$ and $312 \mathrm{bp}$ ) were amplified in the positive control.

An inverse relationship of successful amplification of amplicons with size is a phenomenon that commonly occurs in aDNA samples (Pääbo et al. 2004). As a result, the PCR products observed here are likely to be from genuine aDNA templates of the Batavia samples and were subsequently sequenced. The sequences were compared to the rCRS (Andrews et al. 1999) and differences from the reference sequence were annotated (Tables 3 and 4). Mixtures were present and mainly comprised transitions (C-T/G-A) that may reflect mis-coding lesions often associated with damaged aDNA (Gilbert et al. 2003, 2007). However, the mixtures do not all correspond to described 'hotspots' for damage (Gilbert et al. 2003) and involve mutational pathways aside from $\mathrm{C} \rightarrow \mathrm{T}$ and $\mathrm{G} \rightarrow \mathrm{A}$ (Gilbert et al. 2007). Other possibilities for mixtures include heteroplasmy (more than one mtDNA species), $\mathrm{PCR} /$ sequencing artefacts or contamination. An attempt to clarify the distribution of these mutations for these samples via cloning was unsuccessful.

Consistent with obtaining weak PCR amplicons, sequences of the $217 \mathrm{bp}$ segment corresponding to the HV2 region for most of the samples were poor and did not provide much differentiation between the samples. Aside from possibly A16316 (variation at 228 and 295 relative to others) the samples from the Batavia remains could not be distinguished from one or more control samples. Accordingly, HV2 sequences were only analysed in conjunction with HV1 data. From the HV1 sequences, contamination from the anthropologist (POSD) and the DNA analyst (POSP) could be excluded, as each showed multiple unique variations relative to the other samples. POSH (from the person who did the casting) had a unique variation within HV1 at position 16298, but elsewhere was the same as the positive control. Furthermore, the sample from the dentist (POSF) differed from the positive control at only one site where a mixture was determined (HV2 215). The positive control, POSH, POSD and POSF all came from Caucasian individuals.

The sequences of the HV1 and HV2 regions of the mtDNA for samples SK5, SK6, SK7, A15507 and A15831 and the positive control (POS2) were similar (Tables 3 and 4). Differences were expressed only in mixtures, however, due to poor sequencing results, many areas of sequence were undetermined and hence cannot be used for exclusionary purposes. The possibility that the sequences for SK5, SK6, SK7, A15507 and A15831 arose from the same source, and that contamination occurred from the positive control cannot be ruled-out. Sample M3901 showed one nucleotide difference to POS2 (excluding mixtures) and again contamination for this sample cannot be excluded. Based on these results it is not possible to derive any conclusions regarding the 


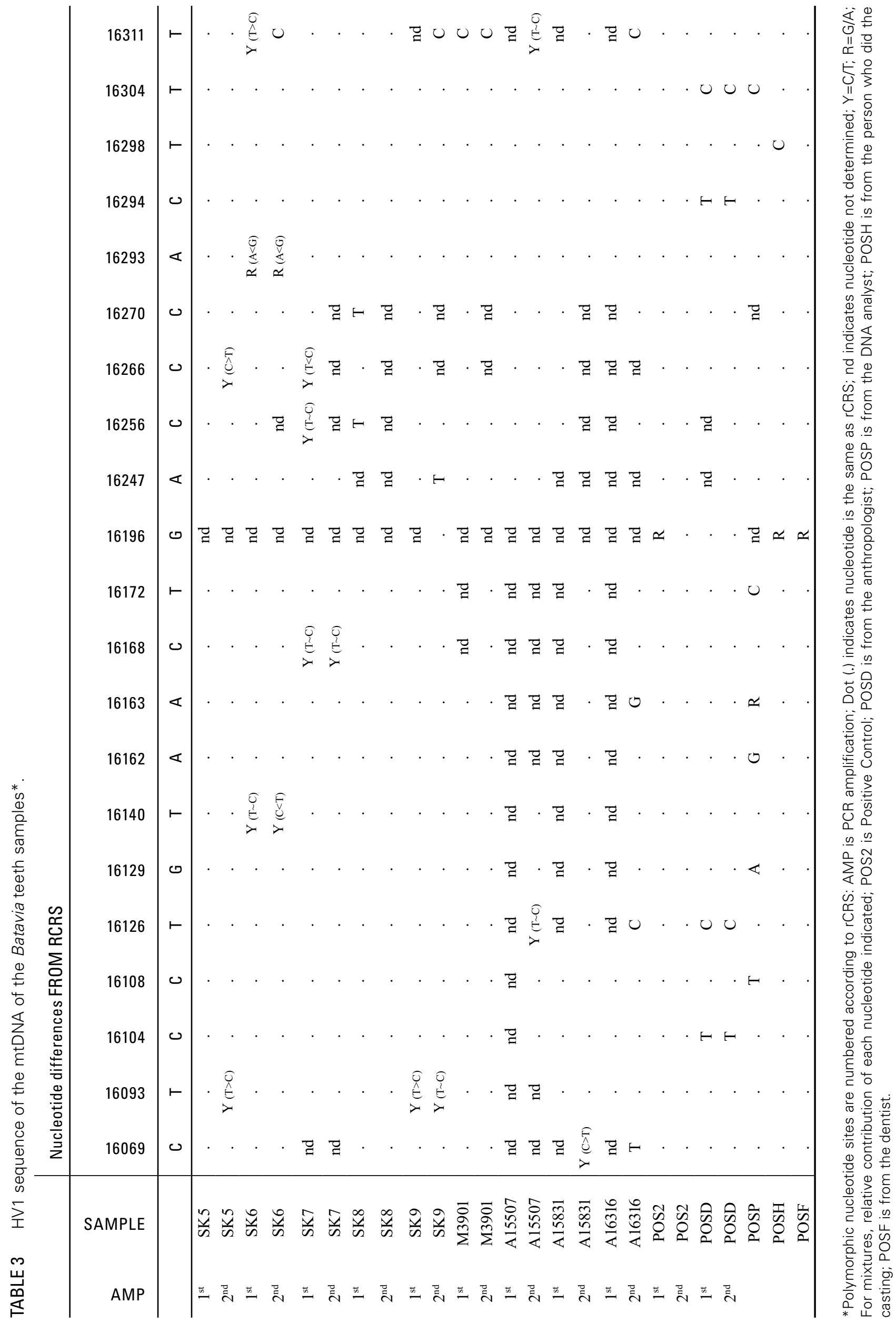


TABLE 4 HV2 sequences of the mtDNA of the Batavia teeth samples*.

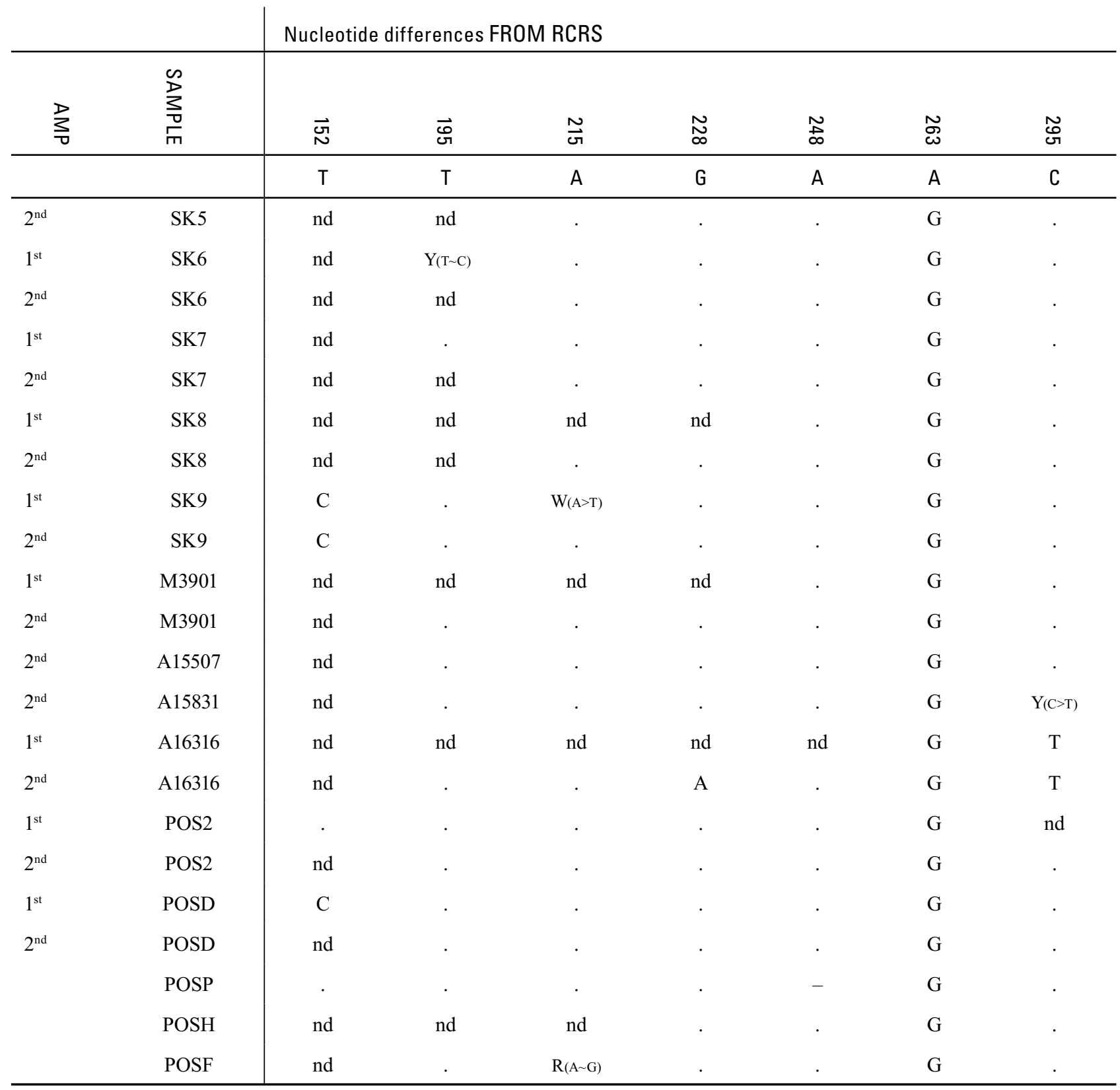

*Polymorphic nucleotide sites are numbered according to rCRS and only sites where a variation relative to the rCRS was observed in a sample or control were included: AMP is PCR amplification; dot (.) indicates nucleotide is the same as rCRS; nd = nucleotide not determined; $Y=C / T ; R=G / A ; W=A / T ;{ }^{\prime}-$ '=deletion; for mixtures, relative contribution of each nucleotide indicated; POS2 is Positive Control; POSD is from the anthropologist; POSP is from the DNA analyst; POSH is from the person who did the casting; POSF is from the dentist. Replicates with poor sequence throughout region were not included.

familial relationships of these six individuals.

Comparison of the HV1 and HV2 sequences of SK8, SK9 and A16316 show that they have different mtDNA sequences. Variations relative to the reference sequence (rCRS) were observed in at least two different nucleotide positions for all combinations, which according to guidelines given by ISFG (Carracedo et al. 2000) and SWGDAM (mtDNA Nucleotide Sequence Interpretation) can be used to exclude the possibility that the sequences come from the same source or maternal lineage. However, one of the variants in SK9 (HV1 16247) was not replicated.
Furthermore, the sequences also show variation in at least two different nucleotide positions from the HV1 and HV2 sequences of the positive control (POS2) as well as persons directly working with the remains (POSD, POSP, POSH and POSF) (Tables 3 and 4).

Specifically, the mtDNA sequence of SK8 shows two variations relative to the $\mathrm{rCRS}$ at nucleotide positions $16256(\mathrm{C} \rightarrow \mathrm{T})$ and $16270(\mathrm{C} \rightarrow \mathrm{T})$ in $\mathrm{HV} 1$, and one variation at nucleotide position $263(\mathrm{~A} \rightarrow \mathrm{G})$ in HV2. No variation was observed at the two nucleotide positions in HV1 for SK9, A16313 and the controls. Although the nucleotides 
MOLECULAR ANALYSES OF BATAVIA MUTINY VICTIMS

105

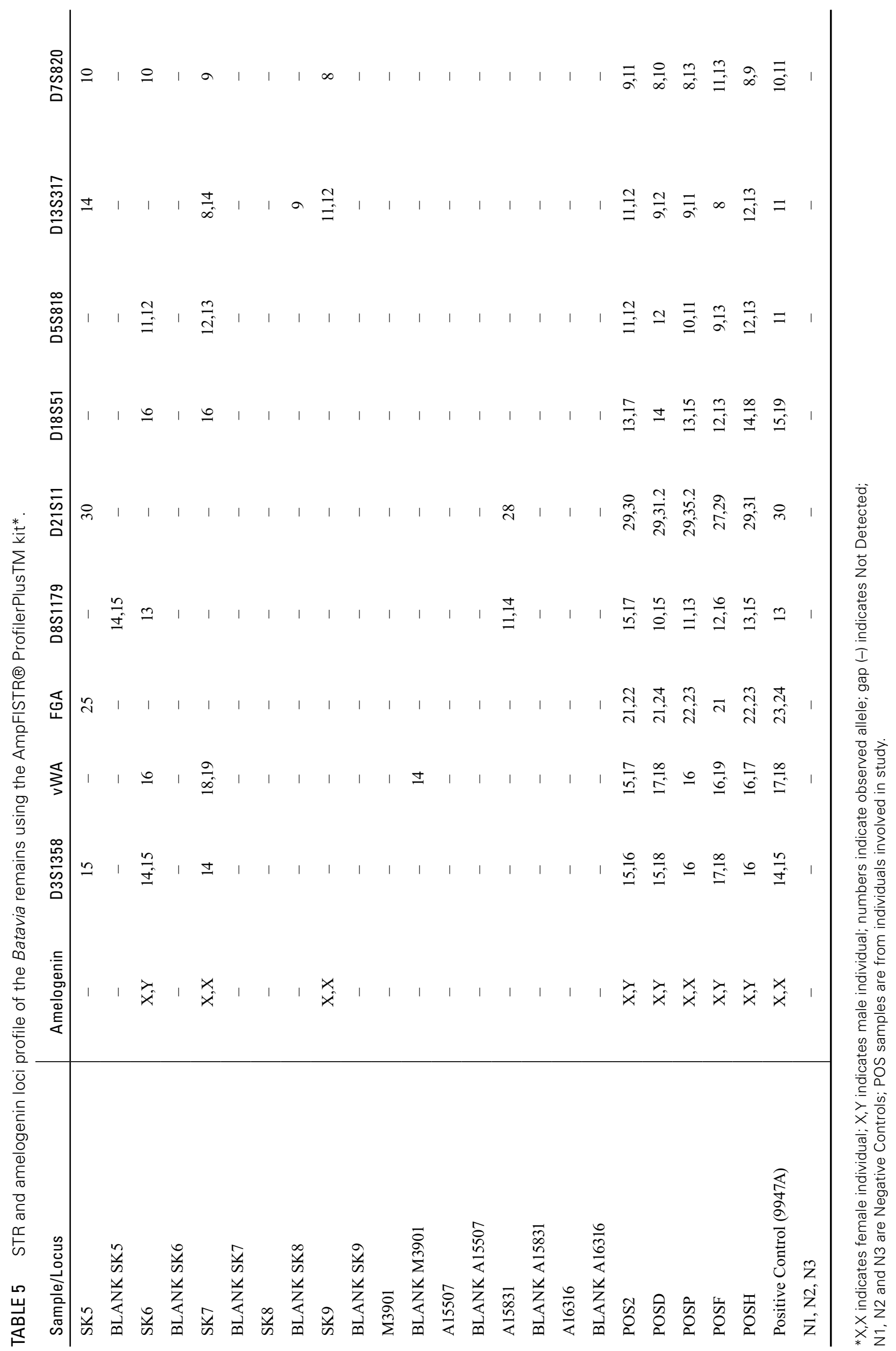


at these positions cannot be determined in all replicates of A16316, this sample showed variation at other positions not observed in SK8 (Tables 3 and 4). It is likely that there is no maternal relationship between SK8 and both SK9 and A16316. Finally, A16316 can be excluded from being maternally related to SK8 and SK9 because it demonstrated several transitions from rCRS at nucleotide positions $16069(\mathrm{C} \rightarrow \mathrm{T}), 16126(\mathrm{~T} \rightarrow \mathrm{C}), 16163(\mathrm{~A} \rightarrow \mathrm{G})$ in HV1 and $228(\mathrm{G} \rightarrow \mathrm{A})$ and $295(\mathrm{C} \rightarrow \mathrm{T})$ in HV2. These polymorphic sites were not observed in SK8 and SK9.

The results described above are not conclusive as the data obtained in this study have not been replicated in a second analysis, but the data does provide some indication of potential relationships (or lack of relationships) between some individuals.

\section{SEX ESTIMATION - AMELOGENIN TYPING}

In this study the method of Sullivan et al. (1993) that targets intron 1 of the amelogenin gene containing a 6 bp deletion on the X-chromosome relative to the Y-chromosome, and the commercial AmpFlSTR ${ }^{\circledR}$ Profiler Plus $^{\mathrm{TM}}$ kit, was used to estimate the sex of the Batavia remains. In the AmpFlSTR ${ }^{\circledR}$ Profiler Plus ${ }^{\mathrm{TM}}$ kit, 9 short tandem repeat (STR)-loci (D3S1358, vWA, FGA, D8S1179, D21S11, D18S51, D5S818, D13S317 and D7S820) and the amelogenin gene (region containing size difference between sex chromosomes) are simultaneously amplified.

Using the Sullivan et al. (1993) method, no PCR products were obtained for any of the skeletal remains. Fragments corresponding to the appropriate sizes were obtained for the two positive control samples (male control exhibited fragments at 106 and $112 \mathrm{bp}$ corresponding to the $\mathrm{X}, \mathrm{Y}$ genotype; female control exhibited one fragment at $106 \mathrm{bp}$ corresponding to the $\mathrm{X}, \mathrm{X}$ genotype; results not shown).

Using the AmpFlSTR ${ }^{\circledR}$ Profiler Plus ${ }^{\mathrm{TM}}$ kit to type the amelogenin gene and 9 STR-loci from the samples had limited success. Partial profiles were observed in samples SK5, SK6, SK7, SK9 and A15831 with amelogenin typing results only for the latter three. The kit positive control (9947A) and control DNA samples from individuals involved in the study (POS2, POSD, POSP, POSF and POSH) were successfully amplified. No peaks were observed above the threshold (50 RFU) in the negative controls. Peaks were observed in the following extraction blanks: D8S1179 locus of Blank SK5; vWA of Blank M3901; and D13S317 of Blank SK8. Comparison of the partial profiles of the remains of SK5, SK6, SK7, SK9 and A15831 with all control samples indicates some unique STR allele combinations at different loci that suggest they may have come from different sources (e.g. presence of alleles 8, 14 at locus D13S317 for SK7; Table 5).

In relation to the amelogenin locus, SK6 exhibits the $\mathrm{X}, \mathrm{Y}$ genotype of a male individual, which concurs with the morphological assessment, whereas SK7 indicates a female individual, contrary to that reported (Table 1). The skeletal remains belonging to the juvenile SK9 also indicates a female individual. However, partial profiles from old remains can indicate DNA degradation, inhibition from the sample itself and/or low amounts of DNA. In these cases, allele dropout (condition where an allele in a heterozygote cannot be visualised, leading to an apparent homozygote, e.g. $\mathrm{X}, \mathrm{X}$ instead of true $\mathrm{X}, \mathrm{Y}$ combination; Whitaker et al. 2001) and allele drop-in (spurious allele - not true allele) are not uncommon and reporting of these partial profiles requires caution. This is further highlighted in this study due to the use of extra PCR cycles (low copy number method) that increases the chance of profile abnormalities and the inability to replicate the amplification due to limited sample volume. Accordingly, no further analysis of the profiles was performed.

The observed difference in the ability of the two amelogenin typing methods to obtain products from amplification of the same samples is probably due to several reasons. First, more template was used in the Profiler Plus amplification. Second, the PCR products of the Sullivan et al. (1993) method were analysed using conventional agarose gel electrophoresis and ethidium bromide staining, while PCR products from the Profiler Plus amplification were analysed using capillary electrophoresis (ABI 3730xl sequencer) and fluorescence dyes; a more sensitive detection method.

\section{DISCUSSION}

\section{FAMILIAL RELATIONSHIPS}

Despite the rigorous contamination precautions taken throughout the analysis of the Batavia teeth samples the HV1 and HV2 regions of the mtDNA sequences of SK5, SK6, SK7, A15507, A15831 and M3901 are similar to the sequences obtained from the positive control sample, as well as the persons working directly on the remains (POSP; POSD; POSH). No assessment was performed on the genetic relationships between these individuals.

From the HV1 and HV2 regions of the mtDNA sequences obtained from SK8, SK9 and A16316, however, it was possible to examine the familial relationships of those individuals, albeit with the caveat that the results should not be treated as conclusive until repetition of the analysis is performed. Based on two or more different polymorphisms observed in SK8, SK9 (buried in the multiple burial) and A16316 (single burial), it is unlikely there is a maternal relationship between those individuals (see Tables 3 and 4). As the genetic evidence suggests that remains of the child and teenager (SK8 and SK9, respectively) are not maternally related, this means that these two individuals cannot be members of the Predicant's family. So, with regard to placing the multiple burial on Beacon Island in its correct historical setting, the theory that these are the remains of sick individuals who were killed early in the massacre remains more plausible (cf. Franklin and Freedman 2006), in consideration of the evidence currently available (see above). 


\section{SEX ESTIMATION}

Although morphological (metric and non-metric) approaches are widely used to estimate the sex of archaeological and forensic skeletal remains, it is difficult to reliably assign sex in the skeleton of subadults (Saunders 1992); in such instances the accuracy of these estimations are considerably reduced (Scheuer 2002; Franklin et al. 2007). From the anthropological analysis of the Batavia skeletons, seven of the adult remains are likely to be male and one is likely female. The sex of the three sub-adult individuals, however, either could not be determined conclusively (SK8) or not at all (SK9 and SK12) (Table 1).

The analysis of the amelogenin gene was only able to provide limited information on the sex of individuals SK6, SK7 and SK9. The male sex of individual SK6, as determined from Profiler Plus, is consistent with the morphological assessment. The sex of SK7, however, was female from the profile, which is not in agreement with the anthropological assessment (Table 1); morphologically the skull of SK7 is amongst the most masculine in the total adult sample (see Franklin and Freedman 2006), which instils some doubt as to the validity of the genetic assessment (see below). The profile of the remains of the five to six year old child (SK9) indicated female sex; morphological sex estimation was not possible (see above).

With regard to the amelogenin gene analyses, it is important to again reiterate that within this particular sample, the accuracy of the assignment of the female genotype $(\mathrm{X}, \mathrm{X})$ is to be regarded cautiously given the sub-optimal results in which profile abnormalities (such as allele drop-out) could have resulted in a single ' $\mathrm{X}$ ' peak. Overall, the limited success in typing the amelogenin gene may have been due to the degradation of the samples and inhibitor effects. The use of a single copy marker (such as the amelogenin gene present on nuclear DNA) is more susceptible to degradation and low DNA quantity compared to mtDNA analysis, due to the greater number of mtDNA copies (can be several hundred) relative to the number of chromosomes (2) per cell.

\section{CONCLUSIONS}

This study described an attempt to use molecular genetic analyses to determine the sex and familial relationships of nine individuals who were recovered from burials on Beacon Island related to the Batavia mutiny of 1629. Although it was possible to extract viable aDNA from a single tooth of each individual, it is clearly apparent that sample degradation and contamination were confounding issues. Nonetheless, the results of this study do have some important ramifications towards establishing the identity of those victims, most importantly that the multiple burial is unlikely to be that of the Predicant's family; independent confirmation of these findings will require the repetition of our analyses.

\section{ACKNOWLEDGEMENTS}

The authors would like to thank the staff of the Western Australian Maritime Museum, especially Myra Stanbury, for access to the Batavia material. Special thanks go to Hans Arkeveld and Frank Arfuso (both of the School of Anatomy and Human Biology) for making the dental casts and the drilling of the teeth, respectively. We would also like to thank David Berryman and Francis Brigg of SABC, Murdoch University, for allowing us to use their ABI3730x1 sequencer and Genemapper software. This project was supported financially by a UWA Research Development Award held by DF; the preparation of this manuscript was supported financially by ARC Discovery Project Grant number DP1092538.

\section{REFERENCES}

Andrews, R., Kubacka I., Chinnery, P., Lightowlers, R., Turnbull, D. and Howell, N. (1999). Reanalysis and revision of the Cambridge reference sequence for human mitochondrial DNA. Nature Genetics 23: 147.

Bouwman, A.S., Chilvers, E.R., Brown, K.A. and Brown, T.A. (2006). Brief communication: identification of the authentic ancient DNA sequence in a human bone contaminated with modern DNA. American Journal of Physical Anthropology 131: $428-431$.

Butler, J.M. (2001). Forensic DNA typing: biology \& technology behind STR markers. Academic Press: Amsterdam.

Carracedo, A., Bar, W., Lincolin, P., Mayr, W., Morling, N., Oilaisen, B., Schneider, P., Budowle, B., Brinkmann, B., Gill, P., Holland, M., Tully, G. and Wilson, M. (2000). DNA Commission of the International Society for Forensic Genetics: guidelines for mitochondrial DNA typing. Forensic Science International 110: 79-85.

Drake-Brockman, H. (1963). Voyage to disaster. Angus and Robertson: Sydney.

Franklin, D. (2001). A bioarchaeological investigation of Beacon Island land sites and the victims of the Batavia mutiny. Unpublished B.Sc. Honours Thesis, School of Anatomy and Human Biology, Centre for Archaeology. University of Western Australia: Perth.

Franklin, D. and Freedman, L. (2006). A bioarchaeological investigation of a multiple burial associated with the Batavia mutiny of 1629. Records of the Western Australian Museum 23: 77-90.

Franklin, D., Oxnard, C.E., O’Higgins, P. and Dadour, I. (2007). Sexual dimorphism in the subadult mandible: quantification using geometric morphometrics. Journal of Forensic Sciences 52: 6-10.

Gilbert, M.T., Willerslev, E., Hansen, A.J., Barnes, I., Rudbeck, L., Lynnerup, N. and Cooper, A. (2003). Distribution patterns of postmortem damage in human mitochondrial DNA. American Journal of Human Genetics 72: 32-47.

Gilbert, M.T., Binladen, J., Miller, W., Wiuf, C., Willerslev, E., Poinar, H., Carlson, J.E., Leebens-Mack, J.H. and Schuster, S.C. (2007). Recharacterization of ancient DNA miscoding lesions: insights in the era of sequencing-by-synthesis. Nucleic Acids Research 35: 1-10.

Hummel, S. (2003). Ancient DNA typing methods, strategies and applications. Springer: Berlin.

Hummel, S. and Hermann, B. (1994). General aspects of sample 
preparation (pp. 59-68). In: Hermann, B. and Hummel, S. (eds), Ancient DNA. Springer-Verlag: NewYork.

Huystee, van M. (ed.) (1998). The Batavia Journal of Francisco Pelsaert. Trans. van Huystee M. Department of Maritime Archaeology, Western Australian Maritime Museum, No. 136.

Kemp, B.M. and Smith, D.G. (2005) Use of bleach to eliminate contaminating DNA from the surface of bones and teeth. Forensic Science International 154: 53-61.

Keyser-Tracqui, C., Crubezy, E. and Ludes, B. (2003). Nuclear and mitochondrial DNA analysis of a 2000-year-old necropolis in the Egyin Gol Valley of Mongolia. American Journal of Human Genetics 73: 247-260.

Meyer, E., Wiese, M., Bruchhaus, H., Claussen, M. and Klein, A. (2000). Extraction and amplification of authentic DNA from ancient human remains. Forensic Science International 113: 87-90.

Paabo, S., Poinar, H., Serre, D., Jaenicke-Despres, V., Hebler, J., Rohland, N., Kuch, M., Krause, J., Vigilant, L. and Hofreiter, M. (2004). Genetic Analyses from Ancient DNA. Annual Reviews of Genetics 38: 645-679.

Palmirotta, R., Verginelli, F., Tota, G., Battista, P., Cama, A., Carmiello, S., Capasso, L. and Mariani-Costantini, R. (1997). Use of a multiplex polymerase chain reaction assay in the sex typing of DNA extracted from archeological bone. International Journal of Osteoarchaeology 7: 605609.

Pasveer, J. (2000). Archaeology. In: M. Stanbury (ed.). Abrolhos Islands Archaeological Sites: Interim Report 5-10, Special Publication No. 5. Australian National Centre of Excellence for Maritime Archaeology: Fremantle.

Pasveer, J., Buck, A. and van Huystee, M. (1998). Victims of the Batavia mutiny: physical anthropological and forensic studies on the Beacon Island skeletons. Bulletin of the Australian Institute for Maritime Archaeology 22: 45-50.

Ricaut, F.X., Kolodesnikov, S., Keyser-Tracqui, C., Alekseev, A.N., Crubezy, E. and Ludes, B. (2006). Molecular genetic analysis of 400-year-old human remains found in two Yakut burial Sites. American Journal of Physical Anthropology
129: $55-63$.

Rudbeck, L., Gilbert, M.T.P., Willerslev, E., Hansen, A.J., Lynnerup, N., Christensen, T. and Dissing, J. (2005). mtDNA analysis of human remains from an early Danish Christian cemetery. American Journal of Physical Anthropology 128: 424-429.

Saunders, S.R. (1992). Subadult skeletons and growth related studies (pp 1-20). In: Saunders, S.A. and Katzenberg, M.A. (eds), The skeletal biology of past peoples: research methods. John Wiley \& Sons: New York.

Scheuer, L. (2002). Brief communication: a blind test of mandibular morphology for sexing mandibles in the first few years of life. American Journal of Physical Anthropology 119: 189-91.

Stanbury, M. (1998). Land archaeology in the Houtman Abrolhos (pp. 101-107). In: Green, J., Stanbury, M. and F. Gaastra (eds), The ANCODS colloquium: papers presented at the Australia-Netherlands colloquium on maritime archaeology and maritime history. Special Publication No. 3. Australian National Centre of Excellence for Maritime Archaeology: Fremantle.

Sullivan, K.M., Mannucci, A., Kimpton, C. and Gill, P. (1993). A rapid and quantitative DNA sex test: fluorescencebased PCR analysis of X-Y homologous gene amelogenin. Biotechniques 15: 636-641.

Whitaker, J.P., Cotton, E.A. and Gill, P. (2001). A comparison of the characteristics of profiles produced with the AMPFISTR ${ }^{\circledR}$ SGM PlusTM multiplex system for both standard and low copy number (LCN) STR DNA analysis. Forensic Science International 123: 217-223.

Wood, W.R. (1990). Ethnohistory and historical method (pp 81-110). In: M.B. Schiffer (ed.), Archaeological Method and Theory. University of Arizona: Tuscon.

Yahya, P. (2008). DNA analysis of human skeletal remains associated with the Batavia mutiny of 1629. Unpublished Master of Forensic Science Thesis, Centre for Forensic Science. University of Western Australia: Perth.

MANUSCRIPT RECEIVED 22 JANUARY 2010; ACCEPTED 20 JULY 2010 